\title{
LA INTRODUCCIÓN DEL PSICOANÁLISIS EN LA LITERATURA ESPAÑOLA A TRAVÉS DE SU REPRESENTACIÓN
}

\author{
Anne-Cécile Druet \\ Université Paris-Est Marne-la-Vallée \\ anne-cecile.druet@u-pem.fr
}

Recibido: 30 junio 2012 ; Aceptado: 17 marzo 2013.

Cómo citar este artículo/Citation: Druet, Anne-Cécile (2013): "La introducción del psicoanálisis en la literatura española a través de su representación", Asclepio, 65 (2): p014. doi: http://dx.doi.org/10.3989/asclepio.2013.14

RESUMEN: En este trabajo se estudia la introducción del psicoanálisis en la literatura española desde la perspectiva de su representación. La introducción del psicoanálisis en España, en las primeras décadas del siglo XX, supuso la aparición de una nueva temática en algunas obras de ficción en las que se hacen referencias explícitas a las teorías psicoanalíticas. El personaje del psicoanalista aparece en el teatro y en la novela, convirtiéndose en portavoz de las ideas freudianas que son expuestas y a veces discutidas en esas obras. Este trabajo se centra en el análisis de esta novedad literaria que constituye un aspecto poco estudiado de la recepción del psicoanálisis en España. Se aborda en primer lugar la cuestión de esos primeros psicoanalistas ficticios. A continuación, se estudian la representación del método terapéutico psicoanalítico y el papel que el psicoanálisis desempeña en las obras analizadas, prestando especial atención a los distintos aspectos de las teorías freudianas que mayor interés parecen haber despertado entre los autores y a las relaciones que guarda este fenómeno con el proceso de introducción del psicoanálisis en el ámbito científico español.

PALABRAS CLAVE: Psicoanálisis; Representación; España; Literatura; Siglo XX.

\section{THE INTRODUCTION OF PSYCHOANALYSIS IN SPANISH LITERATURE THROUGH ITS REPRESENTATION}

ABSTRACT: This article aims to analyse the introduction of psychoanalysis in Spanish literature through its representation. The introduction of psychoanalysis in Spain during the first decades of the 20th century meant the appearance of a new subject in some works of fiction in which psychoanalysis was referred to. Psychoanalysts appeared as characters in a few plays and novels, in which Freudian theories were presented and sometimes discussed. This article focuses on the analysis of this literary innovation, which is an aspect of the reception of psychoanalysis in Spain that has hardly been studied. Firstly, it addresses the question of the first fictional psychoanalysts. Secondly, it addresses the representation of the psychoanalytic therapeutic method and the role played by psychoanalysis in the relevant novels and plays, focusing particularly on the different aspects of Freudian theories that authors seem to have found most interesting, and on the connections between this phenomenon and the introduction of psychoanalysis in Spanish medical circles.

KEY WORDS: Psychoanalysis; Representation; Spain; Literature; 20th century.

Copyright: () 2013 CSIC. Este es un artículo de acceso abierto distribuido bajo los términos de la licencia Creative Commons Attribution-Non Commercial (by-nc) Spain 3.0. 
El objeto de este trabajo es analizar un fenómeno que se inscribe en el campo de la difusión de los saberes de lo mental en el ámbito cultural: la introducción del psicoanálisis en la literatura española. Más precisamente, lo que interesa aquí es un aspecto de este fenómeno - que se podría por supuesto abordar desde diversas perspectivas - que es el de la primera representación del psicoanálisis en la literatura española. Dicho de otro modo, el objeto del análisis no es la cuestión de la influencia de las teorías freudianas en las letras españolas - tema muy amplio que ha dado lugar a múltiples estudios tanto individuales como generacionales - sino la de las características de la aparición del psicoanálisis como una temática nueva en la literatura española.

Esta cuestión, que sepamos, ha sido muy poco estudiada hasta ahora. Algunos de los autores que se han interesado por la entrada del psicoanálisis en España en el ámbito médico aluden a su introducción en la literatura, pero sin ofrecer un estudio global de este fenómeno. Thomas Glick, en particular, dedica algunas páginas de su conocido trabajo "The Naked Science» a este tema, centrándose en algunos de los psicoanalistas ficticios de los años veinte y treinta después de señalar, con humor pero no sin fundamento, que "of the countries where a general debate on the merits of Freud took place in the 1920s and 1930s, Spain must have been the only one to have produced more fictional than real analysts» ["de todos los países en los que tuvo lugar un debate general acerca de los méritos de Freud en los años veinte y treinta, España debe de haber sido el único en producir más psicoanalistas ficticios que verdaderos»] (Glick, 1982, p. 562). Valentín Corcés, por su parte, publicó un artículo sobre el psicoanálisis en la obra de los hermanos Machado, artículo que más tarde incluyó en su ensayo Freud ante Cervantes, pero no amplió el estudio a otros dramaturgos o novelistas cuyas obras son igualmente relevantes para el tema que nos interesa (Corcés Pando, 1989; Corcés Pando, 2005, pp. 57-66). Por lo que hace a la crítica y la historia literaria, se puede mencionar el ensayo de C.B. Morris, Surrealism and Spain, en el que hay un muy breve capítulo titulado «Freud, the Subconscious and the Spanish Stage» que ofrece una suerte de introducción al tema, pero limitada a algunos autores y que no aborda la representación del psicoanálisis como tal (Morris, 1972, pp. 37-40).

Esta cuestión de la representación del psicoanálisis requiere una aclaración metodológica preliminar que atañe a la misma definición de «psicoanálisis» en este contexto. A efectos del presente trabajo, consideramos que hay representación del psicoanálisis en todos aquellos casos en los que aparecen en las obras referencias explícitas a la teoría psicoanalítica, a la práctica terapéutica o al oficio de psicoanalista, cualquiera que sea la relación de los mismos con la orto- doxia freudiana (o en su caso junguiana o adleriana) en la materia. La relación con la ortodoxia sí puede ser un aspecto del análisis en sí, y volveremos sobre este punto más adelante, pero si hacemos de ella un criterio de exclusión a priori, entonces como veremos queda muy poco por estudiar. Por lo tanto, en el planteamiento inicial de este trabajo se utilizan la palabra "psicoanálisis» y sus derivados para referirse a lo que los personajes llaman tal. Por otra parte, si nos centramos en la problemática de la representación y no en la de la influencia, implica que la referencia a Freud por parte de un autor, es decir, las declaraciones de los autores acerca de la utilización de las teorías psicoanalíticas en sus obras, no basten por sí solas para justificar la inclusión de dichas obras en el corpus. La referencia al psicoanálisis tiene que provenir del contenido de la obra para que se pueda considerar que hay representación del mismo ${ }^{1}$.

Una palabra más sobre los límites temporales de este estudio: fue al parecer al final de los años veinte, y más precisamente en la obra Sinrazón de Ignacio Sánchez Mejías estrenada en 1928, cuando apareció por primera vez una representación del psicoanálisis, tal como la hemos definido, en la literatura española. En los cinco años que siguieron al estreno de Sinrazón fueron publicadas en España al menos otras tres obras cuyo contenido justifica su inclusión aquí y que, con Sinrazón, van a constituir nuestro corpus: Las Adelfas de los hermanos Machado (1928), Fedra de Llorenç Villalonga (1932), ambas obras teatrales, y la novela La Túnica de Neso publicada por Juan José Domenchina en 1929. Estas producciones literarias ofrecen una representación del psicoanálisis que puede estudiarse sobre la base de tres aspectos que definen la estructura de este trabajo: el primero es la presencia de un personaje de psicoanalista, el segundo la representación del método terapéutico psicoanalítico, y el último el papel del psicoanálisis en esas obras, es decir, la función literaria que desempeña el psicoanálisis en ellas.

\section{EL PSICOANÁLISIS EN ESPAÑA A FINALES DE LOS AÑOS 1920}

En el momento de la publicación de las obras que se acaban de mencionar, las teorías freudianas han sido ya introducidas en España tanto en la esfera médica como en el ámbito sociocultural ${ }^{2}$. La primera edición de las obras completas de Freud al castellano, iniciada en 1922 , se dará por concluida en 1930 , siendo entonces el psicoanálisis una referencia obligada en todos los órdenes del saber (Carles et al., 2000, p. 139). De forma similar a lo que ocurrió en todos los países en los que se introdujeron las teorías freudianas, estas provocaron en España debates acalorados en los cuales todas las opiniones estuvieron representadas. Debido al contexto histórico y psiquiátrico en el que 
tuvieron lugar, esos debates presentaron en España características específicas, de las que mencionaremos solo algunas que son especialmente relevantes para nuestro estudio. En primer lugar, hasta los años treinta el movimiento psicoanalítico representando la ortodoxia freudiana, la International Psychoanalytical Association (IPA), no contó con ningún miembro español. Al contrario que en otros países, por lo tanto, la corriente psicoanalítica ortodoxa no estuvo presente en España hasta principios de los años treinta y las primeras prácticas psicoanalíticas de la década anterior se hicieron sin que ningún médico tuviera la formación considerada adecuada por la IPA. Lo que se produjo en la práctica médica, en términos generales, fue la incorporación de técnicas psicoanalíticas desvinculadas de su marco teórico y utilizadas junto a otros procedimientos no psicoanalíticos (Carles et al., 2000, p. 179). En segundo lugar, los médicos españoles valoraron el psicoanálisis como método de investigación más que como método terapéutico. Muchos de los introductores de Freud en España reconocían el valor del psicoanálisis en tanto método de investigación de la vida psíquica, tanto normal como patológica, y en tanto método diagnóstico, pero rechazaban su aplicación terapéutica (Carles et al., 2000, p. 179-185).

A finales de los años veinte, en España, Freud también se había convertido en una referencia obligada en los círculos culturales. Como es sabido, los contactos entre los ámbitos culturales y psiquiátricos eran frecuentes en la España de aquellos años. En lo referido al psicoanálisis, un ejemplo de los muchos que podrían ilustrar esta situación es la presencia muy frecuente de los psiquiatras de más prestigio en las páginas de publicaciones culturales, en particular $E I$ Sol, en las que difundían las ideas psicoanalíticas y reseñaban los volúmenes de las obras completas de Freud en castellano. En esas colaboraciones entre las esferas psiquiátrica y cultural cabe destacar el papel de Ortega y Gasset, cuya figura fue igualmente central en la historia de la recepción intelectual de Freud en España. En 1911, Ortega publicó dos artículos en los que presentó las ideas freudianas, el primero en España y el segundo en Argentina (Ortega y Gasset, 2004a; Ortega y Gasset 2004b). A pesar de sus reservas principalmente epistemológicas, el filósofo insistía en la necesidad de conocer y difundir las ideas de Freud, difusión a la que él mismo contribuyó de la forma más determinante: fue por iniciativa suya que se tradujeron las obras completas de Freud al castellano ${ }^{3}$.

\section{EL PSICOANALISTA COMO PERSONAJE}

El personaje del psicoanalista, a veces llamado «psicoanalista", a veces designado como médico psiquiatra que practica el psicoanálisis aparece en cada una de las obras mencionadas más arriba: son los Dres. Ballina en Sinrazón y Carlos Montes en Las Adelfas de los herma- nos Machado, el personaje que no tiene nombre y al que se identifica solo como «El Psicoanalista» en Fedra, y el Dr. Solesio, psicoanalista de la novela La Túnica de Neso. Esos médicos declaran practicar el psicoanálisis, psicoanálisis freudiano todos con la excepción del psicoanalista de Fedra cuya referencia teórica principal es Adler $^{4}$. Dos de ellos trabajan en un manicomio o casa de reposo, uno tiene una consulta privada y el último no ejerce. Además de estos datos profesionales, los autores nos dan a veces algunas informaciones sobre la personalidad o la biografía de esos médicos psicoanalistas. Se nos dice por ejemplo que los Dres. Montes de Las Adelfas y Solesio de La Túnica de Neso estudiaron los dos en Alemania (Machado \& Machado, 1947, p. 58; Domenchina, 1994, p. 35), dato biográfico que estos médicos comparten con muchos de sus colegas de la vida real -entre ellos muchos de los introductores del psicoanálisis en el ámbito médico español- en una época en que era frecuente la ampliación de estudios de medicina en ese país (García \& Herrero, 1995, pp. 133-138). El mismo Ángel Garma, que llegaría a ser el primer psicoanalista español reconocido por la IPA, se estaba formando en Berlín durante esos años (Mom, 1984; Muñoz, 1989; Muñoz, 1993; Carles et al., 2000, pp. 143-151).

En la caracterización de nuestros personajes de psicoanalistas se pone de relieve un rasgo común a todos ellos sin excepción: el hecho de que son médicos «modernos». Esta idea de modernidad del psicoanálisis y de quien lo practica o tiene fe en él aparece de forma explícita repetidas veces en todas las obras. En Las Adelfas, Carlos Montes se describe a sí mismo como «médico a la moderna» (Machado \& Machado, 1947, p. 11), el psicoanálisis es una "nueva ciencia» (Machado \& Machado, 1947, p. 12) y los psicoanalistas «está[n] de moda» (Machado \& Machado, 1947, p. 53). En Fedra la presencia del personaje del psicoanalista es uno de los elementos de "modernización» de la tragedia clásica, es decir, la misma introducción del psicoanalista sirve para anclar la tragedia en un tiempo presente.

Unido a esta idea de modernidad aparece un rasgo de carácter también compartido por esos personajes: son médicos proclives a interesarse por procedimientos nuevos, aun cuando otros los consideran faltos de la debida demostración científica o incluso peligrosos. EI Dr. Ballina de Sinrazón, por ejemplo, es descrito como un hombre seguro de sí mismo, que tiene fe en la posibilidad de curar la enfermedad mental y que opina que más vale experimentar y echar mano de la hipótesis antes que cruzarse de brazos ante la locura y dejar que los locos mueran abandonados en manicomios. Su colega Carrasco no comparte en absoluto su optimismo y le advierte contra la adopción precipitada de nuevos procedimientos que él considera peligrosos: 
Aun dando por ciertas tus observaciones, hace falta una gran audacia para atacar en esa forma tan violenta lo que pudiéramos llamar mentira organizada. Eso solo se puede hacer, sin peligro, cuando se dispone de una gran fuerza. [...] Creo que tú debes tener cuidado con esos ensayos. [...] Me produce una gran alegría oírte hablar, tan seguro, de los nuevos procedimientos, pero insisto. Siempre pienso si no irás demasiado lejos con tu optimismo (Sánchez Mejías, 1976, p. 42).

Esta fe en el psicoanálisis la comparte el Dr. José Solesio de La Túnica de Neso. El Dr. Solesio es un personaje sobre el que tenemos más informaciones que de sus colegas ficticios, pues es objeto de varias descripciones y comentarios en la novela. Tanto las primeras como los segundos son en su gran mayoría despectivos y denigrantes, hasta el punto de rozar lo grotesco. Sin embargo, esta dimensión burlesca no impide que, en la construcción del personaje, Domenchina haya buscado también elementos de verosimilitud, al menos en lo referido al contexto histórico de formación y ejercicio del Dr. Solesio. El dato biográfico ya mencionado de los estudios en Alemania es uno de ellos. Solesio también participa en los debates de la esfera neuropsiquiátrica de su época, y las referencias a esta realidad son frecuentes. Solesio es descrito, por ejemplo, como el «enemigo personal de Simarro» (Domenchina, 1994, p. 35). Al margen de estos elementos históricamente verosímiles, como ya se ha señalado, Domenchina da otros que hacen que el personaje cobre una dimensión que está ausente de las demás obras, pero desde luego no de la producción artística internacional sobre psicoanálisis y psicoanalistas, que es esta dimensión humorística, o en este caso incluso grotesca. Se nos dice por ejemplo de Solesio que como el psicoanálisis no le alcanzaba para vivir hizo oposiciones a Correos y obtuvo plaza, de manera que solo puede atender a sus pacientes los fines de semana y días festivos (Domenchina, 1994, p. 35). Sabemos también que está casado con una mujer frágil de los nervios, que opina que ser psiquiatra consiste en «decir tonterías en alemán» (Domenchina, 1994, p. 46). Domenchina recurre a esta dimensión humorística varias veces en el transcurso de la novela, por ejemplo parodiando algún fragmento de la Psicopatología de la vida cotidiana (Domenchina, 1994, pp. 289-291), o citando ensayos psicoanalíticos imaginarios de títulos tan sugestivos como El chiste y su relación con la taquicardia paroxística o El cáncer sublingual y los epiteliomas labiales como secuela de la supervaloración del objeto sexual (Domenchina, 1994, p. 143). Es de resaltar el hecho de que La Túnica de Neso es la única obra de las que tratamos aquí en la que el psicoanálisis y la figura del psicoanalista se utilizan para fines humorísticos.

Otra cuestión relativa a estos psicoanalistas ficticios, al margen de sus características personales, es, por supuesto, la del papel que desempeñan en la obra en la que aparecen. Como hemos visto más arriba, son todos médicos y es en esta capacidad en la que intervienen en todas las obras, aun cuando también tienen relaciones personales con alguno de los protagonistas. Con excepción de Sinrazón, en que los pacientes del Dr. Ballina son los locos del manicomio, esos médicos atienden a pacientes aquejados de síntomas similares entre los que destacan el insomnio, la falta de apetito, dolores diversos; la palabra "neurastenia" es la que aparece con más frecuencia para caracterizar su estado (Machado \& Machado, 1947, p. 11; Villalonga, 1954, pp. 15, 33; Domenchina, 1994, p. $36)^{5}$. La enfermedad es en esos personajes una característica esencial: se definen como seres enfermos y su vida resulta profundamente marcada por ese estado. "Soy un enfermo y necesito curarme», dice Arturo (Domenchina, 1994, p. 37). Otra vez con la excepción de Sinrazón, estos pacientes son los protagonistas de la obra en la que aparecen, y los psicoanalistas intervienen como personajes secundarios llamados a ayudarlos. En este contexto, el protagonismo de los psicoanalistas varía: a veces es lo suficientemente importante como para que su papel sea decisivo en el desenlace de la obra - para bien o para mal-; pero a veces no, como es el caso de Fedra, donde la tragedia es de entrada inevitable, o de La Túnica de Neso, donde el psicoanalista es uno más de los médicos a los que Arturo pide ayuda en una obra en la que el psicoanálisis es una más de las posibilidades terapéuticas condenadas al fracaso.

Cualquiera que sea su protagonismo, el rasgo fundamental del papel del psicoanalista radica en que viene a ser el portador de la idea de que los síntomas que aquejan a su paciente tienen un origen no somático -llamado "subconsciente», «inconsciente», «moral» o localizado «en el alma»-, que el paciente se oculta a sí mismo pero que puede salir a la luz con la ayuda del psicoanalista. Las formulaciones para expresar esta idea varían, pero es ella la que da sentido a la intervención del psicoanálisis en todas las obras. En Las Adelfas dice Carlos Montes:

No todo / es farsa en la nueva ciencia / del psicoanálisis. Hay / una verdad, aunque vieja / indudable en ella: el alma / puede enfermar. Cuando enferma, / de achaques, lacras y cuitas / del cuerpo puede ser ella / también la causa (Machado \& Machado, 1947, p. 12).

Más adelante añade Montes que su misión consiste en «sacar a la luz» esas verdades escondidas en el fondo del "alma» (Machado \& Machado, 1947, pp. 1213), y su papel queda definido como el de "oír la voz de lo subconsciente» (Machado \& Machado, 1947, p. 66). En Fedra, el psicoanalista deja entender que él "ve» otra cosa que el colega que le precedió, quien había diagnosticado un problema cardíaco:

TESEO. - ¿Qué opina doctor, de la enfermedad de Fedra? 
PSICOANALISTA. - Puedo decir, por de pronto, que no es cardiaca, como opinaba el ilustre colega que me precedió. Su sufrimiento es de índole moral.

TESEO. -EI Dr. Nouvilas le prescribía digitalina.

PSicoAnAlista. - El Dr. Nouvilas es una eminencia, pero...

CARolina. - (A Hipólito) Ahora se dispone a crucificarlo.

PSICOANALISTA. - -...pero en casos como este... No me extraña que en su señora viera una cardiaca. Él no ve otra cosa. Sin embargo, es el espíritu lo que urge analizar (Villalonga, 1954, p. 62).

\section{LA REPRESENTACIÓN DEL PSICOANÁLISIS COMO MÉTODO TERAPÉUTICO}

La intervención del médico en este intento de acceder a las verdades inconscientes se lleva a cabo mediante el método psicoanalítico, o lo que los personajes llaman tal. Lo primero que hay que decir acerca de este método es que en ninguna de las obras lo encontramos representado bajo la forma de una cura psicoanalítica propiamente dicha. Lo que está representado en las obras son o sesiones de psicoanálisis -en aquellos casos como La Túnica de Neso y Sinrazón en los que un paciente acude a un consultorio o es atendido en un manicomio- o simplemente conversaciones entre el médico y su paciente en las que el médico avisa de que está recurriendo al método psicoanalítico.

Estas sesiones o conversaciones son introducidas en todas las obras por explicaciones teóricas acerca de aquellos aspectos de las teorías psicoanalíticas que son los que más relevancia van a cobrar en la obra concernida. Tanto en Las Adelfas como en Sinrazón, estas explicaciones aparecen a los pocos segundos de levantarse el telón. Sinrazón empieza con un debate profesional entre el Dr. Ballina, partidario del psicoanálisis, y su colega Carrasco, que discuten el caso de un paciente supuestamente curado por el método psicoanalítico. Refiriéndose a este paciente, Ballina le dice a su colega: "Te va a producir verdadero asombro la mejoría de ese pobre loco. Bastó descubrirle el origen de su enfermedad para que al momento se iniciara el proceso de su curación» (Sánchez Mejías, 1976, p. 41).

A continuación Ballina emplea por primera vez el término "psicoanálisis" con el sentido siguiente:

Un día sostuve con él una conversación de breves minutos y sobre los elementos que de ella recordaba, hice después el psicoanálisis y quedé plenamente convencido que estaba bajo la influencia de un choque producido por un sentimiento perverso de la sexualidad. Luego, poco a poco, fui sacándole del cuerpo confesiones muy disimuladas al principio, pero que a medida que se estrechaba el cerco se iban aclarando, hasta que por fin, cuando creí llegado el momento oportuno, le descubrí, con violenta sinceridad, mis observaciones (Sánchez Mejías, 1976, pp. 41-42).

Ballina emplea por lo tanto el término «psicoanálisis» para referirse a un proceso llevado a cabo por el mismo médico, un proceso diagnóstico que le lleva a descubrir la etiología sexual de un trastorno ${ }^{6}$. En un segundo momento, el médico consigue que el paciente "confiese» cosas inicialmente "disimuladas», antes de revelarle sus conclusiones.

Encontramos otras explicaciones teóricas sobre el psicoanálisis en boca del Dr. Carlos Montes en Las Adelfas. Después de decirle a Araceli que los males que la aquejan pueden venir del alma, Montes le explica cómo el psicoanálisis se propone curarlos:

Hay una / erotemática nueva, / un arte de partear / espíritus, que es maiéutica / más sutil que la del sabio / Sócrates, si no tan bella, / y consiste en alumbrar / no las divinas ideas, /esas verdades de todos / y nadie, sino las nuestras, / las que cada cual al fondo / sin fondo del alma lleva. / En zonas del alma donde / el candil de la ciencia / - o antorcha o sol, si te place- / no luce ya, o luce apenas, / donde el poeta imagina / el trajinar de colmena / de un mundo creador, nosotros / pensamos que está la negra / mansión de los sueños malos / o el antro donde se engendran. / Deseos que no han podido / cumplirse, turbias y feas / visiones: un mundo inválido / de fracasos y miserias. / Toda una flor malsana, / toda una fauna perversa; / cuando tachó el rojo lápiz / de la moral, o a la excelsa / luz de los sagrados tópicos / de la razón se avergüenza, / allí está, azorado, inquieto, / emboscado entre maleza. / Nuestra misión es sacarlo / a la luz (Machado \& Machado, 1947, pp. 12-13).

Esta idea del psicoanálisis como maiéutica, sobre la que volveremos más adelante, es en el ámbito del análisis de los sueños donde Carlos Montes la va a aplicar. Trata de convencer a la protagonista de Las Adelfas, Araceli, para que le cuente sus sueños, otra vez con una explicación teórica:

Un doctor austríaco / dice que el sueño es guardián / del dormir, que es su contrario. [...] / Los sueños / son cajitas de sorpresa / más que teatro. Y advierte / que el preguntarte en qué sueñas / no fue de curioso, sino / de médico a la moderna. / Sí, los sueños pasaron / de manos de los poetas / a las del médico (Machado \& Machado, 1947, p. 11).

Araceli le cuenta un primer sueño en el que ve a su marido con otra mujer, a la que no puede identificar. Carlos, quien afirma que "los sueños dicen de nuestras sospechas más de lo que sospechamos despiertos» (Machado \& Machado, 1947, p. 16) le hace preguntas, cada vez más precisas, sobre los detalles del sueño, hasta que Araceli acabe identificando a una mujer a la que conoce pero de la que no había 
sospechado nunca, dando así un primer paso en la comprensión del misterio que rodea la muerte de su marido. Al final de la obra será el mismo Carlos quien recordará algo olvidado en circunstancias similares, siendo esta vez Araceli la que pone en práctica ese "arte de preguntar» (Machado \& Machado, 1947, pp. 92-93). En ambos casos las verdades descubiertas gracias al método de Carlos van a revelarse decisivas en el proceso de «curación» de Araceli, quien va a poder liberarse así del pasado.

Este énfasis puesto en los sueños lo encontramos también en Sinrazón de Sánchez Mejías y en La Túnica de Neso de Domenchina. Ambas obras ofrecen representaciones de lo que más se aproxima a sesiones de psicoanálisis. Además de las explicaciones teóricas citadas más arriba, en Sinrazón tenemos dos escenas en las que el Dr. Ballina pone su método terapéutico en práctica, dándonos la oportunidad de observar este método, ya no bajo la forma de un análisis a posteriori sino en la interacción con el paciente. En estas escenas Ballina recibe a dos pacientes del manicomio llamados «El Obispo» y "La Reina» por creerse tales en su locura. Al Obispo le dice que tiene que hablar «sin recelos, sin reservas", e ir "diciendo espontáneamente todo lo que vaya pensando» a partir de una pregunta que hace él o de un recuerdo infantil (Sánchez Mejías, 1976, pp. 62-63). El médico le explica lo que va a hacer: "Yo voy a buscar en tu pensamiento cosas que me interesan para que recobres tu salud. No son las cosas que tú pienses en el momento, sino otras cosas relacionadas con ellas, pero que no tienen, a lo mejor, nada que ver con lo que tú estés pensando» (Sánchez Mejías, 1976, p. 61). El Obispo hace algunas asociaciones, luego se interrumpe; una acotación nos dice entonces que "se resiste a seguir hablando» (Sánchez Mejías, 1976, p. 63). A partir de estas asociaciones y de la interrupción, Ballina afirma haberlo entendido todo y le promete al Obispo que se va a curar. En la segunda sesión de psicoanálisis de la obra, Ballina le pide a la Reina que le cuente el sueño de la noche anterior, sueño en el que la Reina revela estar enamorada de él. Esta revelación de la transferencia es vista como la última verdad que viene a quebrantar el edificio de mentira organizada en el que vivían los personajes (Sánchez Mejías, 1976, pp. 68-69).

Tanto las explicaciones teóricas dadas por Ballina como su actuación durante estas sesiones se corresponden con la definición del llamado «psicoanálisis salvaje» o "silvestre» ${ }^{7}$. Esta definición no excluye la presencia de elementos teóricos o terapéuticos pertenecientes a la ortodoxia freudiana, y es cierto que encontramos en el método de Ballina elementos que remiten a la práctica freudiana ortodoxa, como son la enunciación de la regla fundamental, la asociación libre ${ }^{8}, y$, en menor medida, el papel de la transferencia $^{9}$. Pero al margen de esta mezcla de ortodoxia y de simplificaciones, o incluso de caricatura, el método de Ballina presenta también otras características que tienen que ver ya no con la deformación de las teorías freudianas, sino con la introducción de elementos ajenos a la práctica freudiana ortodoxa, es decir, la introducción de técnicas terapéuticas que no forman parte del psicoanálisis ortodoxo tal como quedaba definido a finales de los años veinte. En primer lugar, Ballina recurre a la sugestión para convencer a sus pacientes de que no son obispo ni reina y de que se van a curar, como vemos en estos fragmentos de la sesión con el Obispo:

BALLINA [al Obispo] - La alegría que producirá a tu padre verte ya en vías de curación. Porque tú te curas. ¡Ya lo creo que te curas! Tú eres hombre de gran voluntad, y observo claramente que la has puesto toda al servicio de tu salud. [...]

BALLINA (Que en su relación con los enfermos ha de usar una gran persuasión con el fin de subyugarlos, de apoderarse de su ánimo) - ¿Tú recuerdas las cosas de tu niñez? [...] Para que yo pueda decirte lo que tú eres, puesto que estamos de acuerdo en que no eres obispo ni siquiera profeso; para que tu curación sea un hecho; para que vuelvas a la posesión de tu personalidad, es preciso, absolutamente indispensable, que me desnudes tu pensamiento [...] porque tú nunca has sido así. [...]

BALLINA - Tú me lo has dicho todo y yo te prometo curarte.

Obispo - ¿Pero curarme de qué?... Yo no soy un enfermo. Yo soy...

BALLINA - Ssss. Tú eres un hombre que está preso en un manicomio porque está enfermo, y vas a salir de él porque yo voy a curarte (Sánchez Mejías, 1976, pp. 60-63).

De forma similar, Ballina le repite a la Reina: «Tú estás enferma. Quedamos ayer en que estás enferma. Tu estás enferma y yo voy a curarte» (Sánchez Mejías, 1976, p. 68).

En segundo lugar, para que se concentren mejor, Ballina les pone una mano en la frente, una técnica como sabemos empleada por Freud en la época en que estaba renunciando a la hipnosis, y más tarde a su vez abandonada y descartada del dispositivo psicoanalítico propiamente dicho ${ }^{10}$.

Si pasamos ahora a observar la sesión de psicoanálisis que aparece en la novela de Domenchina $L a$ Túnica de Neso, nos damos cuenta de que ofrece similitudes con las sesiones de Sinrazón que acabamos de describir, entre otras, esta inclusión de elementos que ya no forman parte del dispositivo psicoanalítico tal y como quedaba definido por Freud a finales de los años veinte. Veamos con algún detalle el relato de esta sesión. Como hemos apuntado más arriba, el protagonista de la novela, Arturo, acude a la consulta 
del psicoanalista, el Dr. Solesio, como una etapa más en una búsqueda de soluciones terapéuticas que no encontrará. A Solesio Arturo lo ve una sola vez, para una única sesión a la que va - como es típico del estilo de la novela - con una mezcla de esperanza y distancia irónica: «A mi neurosis le vendría muy bien un poco de charlatanismo. ¿Por qué no visitar a Solesio?» (Domenchina, 1994, p. 35). Arturo, gran conocedor de la medicina de su época, afirma conocer el psicoanálisis de Freud, pero lo que le exige al médico es que le muestre y le extirpe el "endemoniado complejo" que sería la causa de su malestar ${ }^{11}$. El Dr. Solesio, por su parte, empieza enunciando la regla fundamental en los siguientes términos: "Absténgase de toda crítica. Hábleme de cuanto se le ocurra [...]. No se mortifique en dar forma literaria ni conexión a lo que diga» (Domenchina, 1994, p. 37). Arturo se somete entonces al método de la asociación libre de forma espontánea o a partir de un elemento dado (una imagen de un sueño). Lo primero que se le ocurre son recuerdos de su vida sexual, a lo que sigue un discurso sobre la existencia de Dios, la ética jesuítica y la literatura. Llegados a este punto, el narrador interviene para decirnos que el psicoanalista está «mortalmente aburrido» y decide abandonar las asociaciones libres e intentar el diálogo con Arturo (Domenchina, 1994, pp. 39-40). Le pregunta entonces qué piensa a propósito de las mujeres, y después de otras preguntas y otras asociaciones, el médico se interesa por la infancia de Arturo y por el sueño de la noche anterior. Sobre la base de todos esos elementos, el Dr. Solesio le comunica un diagnóstico. Arturo, dice, "padece una neurosis [...] hondamente enquistada, en lo sexual" (Domenchina, 1994, p. 50). El médico ha deducido dos cosas: la primera es que Arturo se masturba, y la segunda que está inconscientemente enamorado de su suegra. A petición de Arturo le explica el proceso interpretativo:

Me habló usted en un principio de Graciela. Usted y Graciela, conjuntos en un banco, se ven sorprendidos. Y usted, en su sorpresa, cita a Crates. Bien. Crates fue un ilustre discípulo de Diógenes. ¿Comprende? Y Diógenes, a su vez, un sectario de Onán. ¡Estupendo! Al hablarme de su última novia, y de pasada, usted me hizo saber que, sin causa, solía decirla: «Con diez años más estarás más sugestiva». Lo que vale tanto como: me gustarás más cuando envejezcas, cuando te parezcas más a tu madre. Me habló usted, luego, de Nerón. Nerón, para usted y para mí, significa: Nerón y su madre: incesto [...] Pero hay más. Confesó usted acto seguido, que de los síntomas que le aquejan el que más le angustia son las palpitaciones. La relación es obvia. Las palpitaciones son muy frecuentes en individuos que se masturban. (Ah, y olvidaba su alusión a los jesuitas, tan sugerente) (Domenchina, 1994, pp. 52-53).

Dejando a un lado la discusión sobre estas interpretaciones silvestres y la dimensión humorística que está siempre presente en Domenchina, cabe señalar que en el transcurso de la sesión, Solesio practica también con Arturo las "experiencias de asociación» (Domenchina, 1994, p. 49), el estudio de las reacciones y de los tiempos de reacción a palabras inductoras, técnica como sabemos elaborada por la Escuela de Zurich y en particular por Jung. El mismo Freud reconocía el interés de este procedimiento, como lo explicó en las ya citadas conferencias estadounidenses de 1909, pero no llegó a hacer de él un elemento constitutivo de la técnica psicoanalítica (Freud, 1994, p. 28). El uso del término complejo, que aparece en cursiva en la novela, tanto en boca de Arturo como en la del médico para referirse a lo que el psicoanálisis tiene que identificar y curar, también remite a Jung y a la escuela de Zurich ${ }^{12}$.

Tanto en el caso de Sinrazón como en el de La Túnica de Neso, encontramos por lo tanto desde el punto de vista técnico una mezcla de elementos claramente identificables como conformes a las recomendaciones de Freud en la materia, y de otros elementos que no forman parte del dispositivo psicoanalítico tal y como quedaba definido por él en el momento de la aparición de estas obras. Estos últimos elementos no son en su mayoría artificios literarios, sino técnicas que formaron parte de la prehistoria del psicoanálisis o que pertenecen a otras escuelas de psicoanálisis, es decir, son psicoanalíticas pero no llegaron a ser incluidas en el dispositivo freudiano ortodoxo. A este respecto, es interesante notar que la técnica de asociación verbal de Jung que acabamos de ver utilizada en la literatura tuvo mucho éxito entre los psiquiatras españoles, que recurrían con frecuencia a ella con la finalidad de poner de manifiesto los "complejos», al tiempo que criticaban la libre asociación de Freud, que no ofrecía las mismas posibilidades de convertirse en un instrumento diagnóstico preciso (Carles et al., 2000, pp. 188-194) $)^{13}$.

En el caso de otras representaciones literarias tempranas del psicoanálisis, en particular la más conocida de ellas, la novela de Italo Svevo La coscienza di Zeno publicada en 1923, se ha analizado la representación del tratamiento psicoanalítico en términos de deformación, simplificación o caricatura tomando como referencia la ortodoxia freudiana, y se ha tratado de averiguar si, y en qué medida, estas deformaciones respondían a una decisión del autor o más bien eran involuntarias y se debían a un conocimiento superficial de las teorías freudianas (Fusco, 1976, pp. 57-79; Musatti, 1976; Lavagetto, 1986, pp. 55-56; Palmieri, 1994; Genco, 1998). Este tipo de análisis en términos de distorsiones voluntarias o involuntarias con respecto a unas técnicas analíticas normativas parece menos pertinente en el caso de los autores españoles, quienes ciertamente habían leído a Freud pero, al contrario que Svevo, no tenían contacto con la cuna del psicoanálisis o con personas directamente vinculadas 
a ella. Su principal modelo era muy probablemente la práctica psicoanalítica tal y como se entendía en la España de los años veinte, es decir, como hemos visto, una práctica que de por sí no era normativa. Por otra parte, estos autores habían leído a Freud, pero es muy probable que lo leyeran en la traducción española de Biblioteca Nueva que, como se sabe, no siguió el orden cronológico de los originales; no significa, por lo tanto, que hubieran leído todo lo que Freud había publicado a finales de los años veinte sobre la técnica analítica. En el caso de Sánchez Mejías, se ha señalado el hecho de que no había leído ninguna de las obras en las que Freud hablaba de psicosis y de su tratamiento psicoanalítico, puesto que ninguna de estas formaba parte de los tomos publicados por Biblioteca Nueva antes de 1928 (Acuña Gallego y Angosto Saura, 2011, p. 188). Dicho de otra manera, la realidad que hay que tener en cuenta si se quiere determinar el grado de deformación literaria del método psicoanalítico en Domenchina y en Sánchez Mejías es la realidad de la práctica en el ámbito psiquiátrico español más que la de una práctica freudiana ortodoxa que, como hemos visto, aún no existía en el país ${ }^{14}$. El caso de la introducción del psicoanálisis en la literatura española sería por lo tanto una de esas situaciones en las que el impacto de un saber nuevo no proviene en línea directa de este saber sino del paso de este saber por una etapa intermediaria, que en este caso sería su recepción en el ámbito médico español.

\section{LA FUNCIÓN LITERARIA DEL PSICOANÁLISIS}

Acabamos de aludir a una posible perspectiva comparada entre La coscienza di Zeno y nuestras obras españolas, especialmente La túnica de Neso, por tratarse ambas de novelas. Un aspecto fundamental de este análisis comparado radica en la función literaria del psicoanálisis en las obras en las que se encuentra representado. Italo Svevo escribió en su famosa carta a Valerio Jahier que Freud era "un gran hombre, pero más para los escritores que para los enfermos» (Svevo, 1968, p. 857). Uno de los personajes de La Túnica de Neso hace una afirmación similar al decir que «la psicoanálisis es un descubrimiento precioso para la literatura, pero no puede incluirse de buena fe en la terapéutica» (Domenchina, 1994, p. 81). Ambos autores parecen haber dado una traducción literal a esta idea en sus respectivas obras. En La Túnica de Neso, en efecto, el psicoanálisis es denigrado en tanto método terapéutico, pero cumple varias funciones literarias, es decir, es utilizado por el autor en la misma construcción de su novela. El personaje del Dr. Solesio recibe una serie de calificativos más despectivos los unos que los otros; se nos dice que «une a su imbecilidad congénita una fe absurda en ese alegre judío que hace, muy divertidamente, literatura patológica» (Domenchina, 1994, p. 51), y Arturo considera que está peor después del psicoanálisis que antes (como Zeno, por cierto, en sus memorias) ${ }^{15}$. Pero al mismo tiempo, Domenchina usa el psicoanálisis como resorte de su obra poniendo énfasis en los sueños, en los actos fallidos y en los olvidos de su personaje que están presentes en toda la novela. Domenchina, por lo tanto, proporciona un abundante material identificado por el psicoanálisis como vía de acceso al inconsciente y pertinente para un análisis de tipo psicoanalítico, legitimando así el uso literario de una teoría que al mismo tiempo denigra en su vertiente terapéutica ${ }^{16}$.

La valoración del psicoanálisis como modo de sacar a la luz las motivaciones inconscientes de los personajes es, como hemos visto, una característica compartida por todos los autores. En Las Adelfas de los hermanos Machado, este proceso de revelación de los contenidos inconscientes se hace principalmente a través de los sueños y de la interpretación de los mismos. El psicoanálisis es definido en la obra como una maiéutica o un "arte de preguntar», lo que parece reflejar la opinión de los autores que hablaban de las teorías freudianas de forma similar (Corcés Pando, 2005, p. 58). Las verdades descubiertas gracias a este método se revelan decisivas en el proceso de «curación» de la protagonista, Araceli, que va a poder liberarse así del pasado. En Sinrazón, en la que el sueño también tiene una presencia significativa, es también a través del recurso al psicoanálisis durante esas sesiones que hemos analizado más arriba que emerge la verdad hasta entonces disimulada a la conciencia del sujeto. Que el psicoanálisis permita la emergencia de la verdad es algo que en estas obras no se cuestiona. Lo que sí da lugar a un cuestionamiento es la revelación de la verdad en sí, es decir, esta verdad, ¿̇hay que desvelarla o es mejor que el sujeto siga ignorándola? En Sinrazón, esta cuestión es objeto de un debate explícito entre el partidario del psicoanálisis, Ballina, y su detractor, Carrasco, quien opina que «no hay nada más peligroso que meter la verdad como una cuña en un bloque sólidamente formado por la mentira» (Sánchez Mejías, 1976, p. 42). En la obra Ballina acabará dándole la razón a Carrasco, y el desenlace de la historia no hará sino confirmar la idea de que conocer la verdad -en este caso la verdad descubierta por el psicoanálisispuede llevar al desastre. En Las Adelfas, en cambio, la revelación de los contenidos reprimidos del sueño lleva a Araceli a poder liberarse de un pasado del que era prisionera y cuyo peso le impedía vivir.

Aun en aquellos casos en que el tratamiento psicoanalítico es visto como peligroso o condenado al fracaso, encontramos por lo tanto este recurso al psicoanálisis como un método nuevo que permite revelar verdades que el sujeto se oculta a sí mismo. El énfasis puesto en las motivaciones inconscientes de los personajes, el recurso a los sueños y en menor medida a los actos fallidos en la misma construcción de las 
obras, como modo de desvelar algo más de la verdad de cada uno, es lo que, al parecer, mayor interés despertó entre los autores, fuera cual fuera su valoración del psicoanálisis como método terapéutico, que como hemos visto difiere de una obra a otra.

Lo que distingue las obras presentadas aquí del incalculable número de producciones literarias influenciadas por las teorías freudianas es que encontramos en ellas una representación, como se ha dicho, no tanto de una ortodoxia psicoanalítica cuanto de la

\section{NOTAS}

1 Este criterio explica por ejemplo la exclusión de una novela como El Doctor Inverosímil, en cuyo prólogo Gómez de la Serna llama «psicoanálisis» a las intervenciones del médico pero en la que no encontramos, salvo error de mi parte, referencias explícitas al psicoanálisis en el transcurso de la obra. Otras obras que se citan con frecuencia en estudios sobre la influencia de Freud en la literatura española de los años veinte y treinta, tales como Brandy, mucho brandy de Azorín, se han excluido por razones similares.

2 Sobre la introducción del psicoanálisis en el ámbito médico español, véanse, entre otros, Glick (1982); Carpintero \& Mestre (1984); Corcés Pando (1992); Glick (1988) y Carles, Muñoz, Llor \& Marset (2000). Sobre la recepción del psicoanálisis en el ámbito cultural, véanse, entre otros, Corcés Pando (2005) y Lázaro (1991). Un estudio historiográfico más detallado puede encontrarse en Druet (2006) y Druet (2007).

3 Sobre Ortega y Gasset y el psicoanálisis, véase, entre otros, García Lara (1997).

4 Refiriéndose a Fedra, el personaje del psicoanalista dice que "cae de lleno dentro del punto de vista adleriano» (Villalonga, 1954, p. 37). Más adelante añade: «La enferma pertenece, posiblemente, al tipo clasificado por Adler como neurosis por voluntad de dominar» (Villalonga, 1954, p. 63).

5 Incluso en Sinrazón, el paciente curado por Ballina parecía padecer neurastenia, aunque esta palabra no aparece en la obra (Acuña Gallego y Angosto Saura, 2011, p. 183).

6 Se encuentra esta expresión, «hacer el psicoanálisis», empleada con este mismo sentido, en la literatura médica española de la época. Con respecto al campo semántico entonces cubierto por la palabra "psicoanálisis», Carles et al. (2000, p. 186) escriben: "Lo primero que Ilama la atención al revisar los trabajos publicados [sobre la técnica psicoanalítica en España] es el sentido con que utilizaron el término 'psicoanálisis'. Más que designar a un método específico, con características peculiares, se refieren a un análisis psíquico un poco más detenido que una simple anamnesis».

7 «Dans un sens large, type d'interventions d'analystes amateurs ou inexpérimentés qui s'appuient sur des notions psychanalytiques souvent mal comprises pour interpréter des symptômes, des rêves, des paroles, des actions, etc. Dans un sens plus tech- situación del psicoanálisis en la España de finales de los años veinte. Por esta razón, y dejando a un lado la discusión sobre su calidad literaria — ninguna de ellas ha conocido la suerte de La coscienza di Zeno-, estas obras forman parte de pleno derecho de la historia del psicoanálisis en España. Los vínculos entre esta primera representación del psicoanálisis en la literatura y la introducción de este saber en el ámbito médico son una clara ilustración - distinta y complementaria de la cuestión de las influencias - del impacto cultural de la difusión del psicoanálisis en España.

nique, on qualifiera de sauvage une interprétation qui méconnaît une situation analytique déterminée, dans sa dynamique actuelle et sa singularité, notamment en révélant directement le contenu refoulé sans tenir compte des résistances et du transfert» [«En un sentido amplio, tipo de intervenciones de "analistas» aficionados o inexpertos que se basan en conceptos psicoanalíticos que muchas veces no entienden de forma adecuada para interpretar síntomas, sueños, palabras, acciones, etc. En un sentido más técnico, se calificará de "salvaje» una interpretación que desatiende una situación analítica determinada en su dinámica actual y en su singularidad, en particular cuando revela directamente el contenido reprimido sin tener en cuenta las resistencias y la transferencia»] (Laplanche \& Pontalis, 2002, p. 353).

8 Al inicio de la sesión con el Obispo, el Dr. Ballina le dice lo siguiente: "Yo voy a buscar en tu pensamiento cosas que me interesan para que recobres tu salud. No son las cosas que tú pienses en el momento, sino otras cosas relacionadas con ellas, pero que no tienen, a lo mejor, nada que ver con lo que tú estés pensando. Cuando pensamos una cosa y discurrimos sobre ella van surgiendo otras y otras, y las últimas, a lo mejor, no tienen nada que ver con las primeras, como si fueras enlazando muchos aros, unos con otros, para formar una cadena, $y$, aunque todos se tocan sucesivamente, el último está muy distante del primero» (Sánchez Mejías, 1976, pp. 61-62).

9 El psicoanalista Emilio Valdivielso Miquel opina incluso que la forma en que Sánchez Mejías explica la teoría de los sueños y la noción de conflicto neurótico es admirable, y que se aprecia con gran fuerza el conocimiento profundo que Sánchez Mejías tenía del psicoanálisis (Valdivielso Miquel, 1977, pp. 79-80).

10 Freud habla del uso de esta técnica y explica las razones que lo llevaron a abandonarla en la segunda de las conferencias pronunciadas en la Clark University en 1909 (Freud, 1994, p. 20).

11 Dice Arturo al médico: "Yo no me voy de aquí mientras usted no me muestre, con el ademán cursi de odontólogo que nos hace admirar el hueso careado que acaba de extraernos, ese endemoniado complejo, que tiene usted la obligación de extirparme» (Domenchina, 1994, p. 46, cursiva en el original).

12 Aunque el mismo Freud también utilizó el término complejo con este sentido, ya en los años 1910 criticaba esta utilización (Laplanche \& Pontalis, 2002, pp. 72-73). En España, en cambio, 
esta palabra aparecía con frecuencia en la literatura médica de la década siguiente asociada a la técnica de la Escuela de Zurich (Carles et al., 2000, pp. 188-194).

13 El interés que despertó la prueba de Jung entre los médicos españoles partidarios del psicoanálisis se ve reflejado en el hecho de que en la primera monografía publicada en España sobre psicoanálisis, El Psico-Anàlisi, Emilio Mira y López dedica un capítulo entero a esta técnica. Sobre esta cuestión, Carles et al. (2000, p. 194) concluyen que «a pesar de conocer [los psiquiatras españoles] el procedimiento freudiano más importante, prefirieron acudir al de Jung a causa de su susceptibilidad para convertirse en un instrumento clínico preciso (matemático como una fórmula leucocitaria) que ofrecía la posibilidad de adentrarse en los secretos de la mente como hasta entonces ninguno había podido hacerlo. Por este motivo se convirtió en una de las técnicas más apreciadas del arsenal diagnóstico psiquiátrico».

14 En el caso de Sinrazón, hay quien opina incluso que el personaje del Dr. Ballina se basaba en la figura de Gonzalo Rodríguez Lafora (Gallego Morell, 1976, p. 21). Thomas Glick comparte esta opinión y subraya los puntos comunes entre los métodos de ambos médicos: "Probably the guess is correct, because Ballina's description of his therapeutic method is similar to the shortened analytic procedure used by Lafora. [...] Dramatic license aside [...] this method accords well with Lafora's descriptions [...] of his own modus operandi» [«Esta hipótesis es probablemente correcta

\section{BIBLIOGRAFÍA}

Acuña Gallego, María J. y Angosto Saura, Tiburcio (2011), "Las ideas psiquiátrico psicoanalíticas en la obra literaria del torero Ignacio Sánchez Mejías". En: Martínez Azumendi, Óscar; Sagasti Legarda, Nekane y Villasante, Olga (eds.), Del pleistoceno a nuestros días. Contribuciones a la historia de la psiquiatría, Madrid, Asociación Española de Neuropsiquiatría, pp. 177-192

Ardolino, Francesco y Druet, Anne-Cécile (2005), "La psychanalyse racontée par Italo Svevo", Savoirs et cliniques, 6, pp. 75-80.

Carles, Francisco; Muñoz, Isabel; Llor, Carmen y Marset, Pedro (2000), Psicoanálisis en España (1893-1968), Madrid, Asociación Española de Neuropsiquiatría.

Carpintero, Helio y Mestre, María V. (1984), Freud en España. Un capítulo de la historia de la psicología en España, Valencia, Promolibro.

Corcés Pando, Valentín (1989), “Antonio Machado y el psicoanálisis", Revista de la Asociación Española de Neuropsiquiatría, 9 (31), pp. 597-604.

Corcés Pando, Valentín (1992), La recepción del psicoanálisis en España. Estudio de su prehistoria (1893-1936), Tesis doctoral, Universidad Complutense de Madrid.

Corcés Pando, Valentín (2005), Freud ante Cervantes. El psicoanálisis y la cultura española en el primer tercio del siglo XX, Valencia, Promolibro. porque la descripción que hace Ballina de su método terapéutico se asemeja al procedimiento analítico abreviado que usaba Lafora [...] Licencia dramática aparte [...] este método corresponde bastante bien con las descripciones que hace Lafora de su propio modus operandi»] (Glick, 1982, pp. 562-563). El mismo Lafora, sin embargo, criticó la actitud de Ballina en su reseña de Sinrazón, describiéndolo como «aquel cándido alienista que se llama progresivo porque descubre a Freud cuando están en declinación sus mejores concepciones teóricas, y todavía quiere 'curar' las psicosis de cualquier género con el psicoanálisis de los conflictos reprimidos, hoy, que el psicoanálisis es ya, en la mayoría de los casos, solo un medio de conocer y reformar, pero no de curar bruscamente al enfermo» (citado por Carles et al., 2000, p. 129). En opinión del psicoanalista Emilio Valdivielso Miquel, Ballina no es Lafora sino el padre de Sánchez Mejías, don José, que también era médico (Valdivielso Miquel, 1977, p. 89).

15 Zeno dice: «L'ho finita con la psico-analisi. Dopo di averla praticata assiduamente per sei mesi interi sto peggio di prima» [ «Ya no quiero saber nada del psicoanálisis. Después de haberlo practicado asiduamente durante seis meses enteros, estoy peor que antes»] (Svevo, 1969, p. 928), y Arturo: «Los síntomas de mi neurosis no decrecen. Algunos [...] se agudizan» (Domenchina, 1994, p. 64).

16 Sobre esta misma cuestión en Svevo, véase Ardolino \& Druet (2005).

Domenchina, Juan José (1994), La Túnica de Neso, Madrid, Biblioteca Nueva (original de 1929).

Druet, Anne-Cécile (2006), “Historiografía del psicoanálisis en España (1975-1985)", Archivos de Psiquiatría, 69 (3), pp. 197-217.

Druet, Anne-Cécile (2007), “La psychanalyse en Espagne: un bilan historiographique", Mélanges de la Casa de Velázquez, 37 (2), pp. 223-241.

Freud, Sigmund (1994), "Cinco conferencias sobre psicoanálisis (1910 [1909])". En: Obras Completas, vol. XI, Buenos Aires, Amorrortu, pp. 7-51.

Fusco, Mario (1976), "Italo Svevo e la psicanalisi”. En: Petronio, Giuseppe (ed.), Il caso Svevo, Palermo, Palumbo, pp. 57-79.

Gallego Morell, Antonio (1976), “Prólogo”. En: Sánchez Mejías, Ignacio, Teatro, Madrid, Ediciones del Centro, pp. 7-31.

García, Emilio y Herrero, Fania (1995), "Neuropsiquiatría y psicología en España en el primer tercio del siglo XX. El papel de la JAE". En: Un Siglo de Psiquiatría en España, Madrid, Extra Editorial, pp. 111-138.

García Lara, Carlos Enrique (1997), Ortega y el psicoanálisis, Alicante, Universidad de Alicante.

Genco, Giuseppe (1998), Italo Svevo. Tra psicanalisi e letteratura. Nápoles, Alfredo Guida. 
Glick, Thomas (1982), "The Naked Science: Psychoanalysis in Spain 1914-1948", Comparative Studies in Society and History, 24, pp. 533-571.

Glick, Thomas (1988), "El impacto del psicoanálisis en la psiquiatría española de entreguerras". En: Sánchez Ron, José Manuel (dir.), Ciencia y sociedad en España, Madrid, El Arquero/CSIC, pp. 205-221.

Laplanche, Jean y Pontalis, Jean-Bertrand (2002), Vocabulaire de la psychanalyse, París, Presses Universitaires de France.

Lavagetto, Mario (1986), L'impiegato Schmitz e altri saggi su Svevo, Torino, Einaudi.

Lázaro, José (1991), "La recepción de Freud en la cultura española (1893-1983)", Medicina e Historia, 41, pp. 5-28.

Machado, Manuel y Machado, Antonio (1947), Las Adelfas, Buenos Aires, Espasa-Calpe (original de 1928).

Mom, Jorge M. (1984), “Entrevista a los fundadores (I): Ángel Garma", Revista de Psicoanálisis (Buenos Aires), 40 (5-6), pp. 899-914.

Morris, Cyril Brian (1972), "Freud, the Subconscious and the Spanish Stage". En: Surrealism and Spain. 1920-1936, Nueva York, Cambridge University Press, pp. 37-40.

Muñoz, María L. (1989), “Contribución a la historia del movimiento psicoanalítico en España: la formación de la Asociación Psicoanalítica de Madrid", Revista de Psicoanálisis de Madrid, número extraordinario, mayo-noviembre, pp. 121-152.
Muñoz, María L. (1993), "Ángel Garma y la historia del movimiento psicoanalítico en España", Papeles del Psicólogo, 56, pp. 66-67.

Musatti, Cesare (1976), "Svevo e la psicoanalisi". En: Riflessioni sul pensiero psicoanalitico, Turín, Boringhieri.

Ortega y Gasset, José (2004a), "Psicoanálisis, ciencia problemática". En: Obras completas, Vol. 1, Madrid, Taurus, pp. 482-501 (original de 1911).

Ortega y Gasset, José (2004b), "Nueva medicina espiritual". En: Obras completas, Vol. 1, Madrid, Taurus, pp. 473-481 (original de 1911).

Palmieri, Giovanni (1994), Schmitz, Svevo, Zeno. Storia di due biblioteche, Milán, Bompiani.

Sánchez Mejías, Ignacio (1976), “Sinrazón”. En: Teatro, Madrid, Ediciones del Centro, pp. 39-70 (original de 1928).

Svevo, Italo (1968), "Lettera a Valerio Jahier". En: Opera omnia, Vol. 1, Milán, dall’Oglio, p. 857.

Svevo, Italo (1969), La coscienza di Zeno. En Opera omnia, Vol. 2, Milán, dall’Oglio.

Valdivielso Miquel, Emilio (1977), “Apunte histórico sobre el movimiento psicoanalítico en España: Ignacio Sánchez Mejías", Boletín del Grupo de Estudios Psicoanalíticos de Madrid, (1), pp. 76-94.

Villalonga, Lorenzo (1954), Fedra, Palma de Mallorca, Atlante (original de 1932). 